\title{
Effect of Vitamin D supplementation on symmetric dimethyl arginine, asymmetric dimethyl arginine, homocysteine levels in rats being exposed to gamma radiation
}

\author{
Erdem Kahraman', Durmuş Ayan², Aysel Arıcıoğlu³, Müge Akmansu ${ }^{4}$ \\ ${ }^{1}$ Lecturer, ${ }^{3}$ Professor, Department of Medical Biochemistry, Gazi University Faculty of Medicine, Ankara. Turkey, \\ ${ }^{2}$ Specialist of Medical Biochemistry, Department of Medical Biochemistry, Niğde Education and Training Hospital, \\ Niğde. Turkey, ${ }^{4}$ Professor, Department of Radiation Oncology, Gazi University Faculty of Medicine, Ankara. Turkey
}

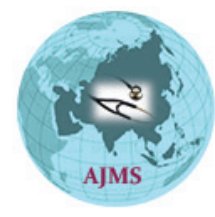

\section{A B S T R A C T}

Background: Radiation causes to damage on endothelial cells by increasing oxidative stress. Vitamin $D$ is also a potent anti-oxidant that facilitates balanced mitochondrial activities, preventing oxidative stress-related protein oxidation, lipid peroxidation, and DNA damage. Aims and Objective:We aimed to investigate the potential effect of vitamin D supplementation on levels of Hcy (homocysteine), ADMA (Asymmetric Dimethyl Arginine), and SDMA (Symmetrical Dimethyl Arginine) which are admitted as endothelial dysfunction markers in rat models that are exposed to gamma radiation. Materials and Methods: Twentyfour female Wistar Albino rats were selected for the study. The mean weight of these rats were between 200 and 250 grams. Rats were fed with standard light (12 hours day light / 12 hours dark), enough water (ad-libitum) at temperature $\left(25^{\circ} \mathrm{C}\right)$ for a total of 4 weeks. The rats were divided into 4 different groups and each group consisted of 6 rats. controlgroup (group I) did not receive any supplementation and not expose to gamma radiation), Group II was merely exposed to gamma radiation, Group III was exposed to gamma radiation and received vitamin D supplementation, and Group IV merely received vitamin D supplementation. Groups that are given vitamin D supplementation were fed by oral gavage at the same time and every day for one week. Finally, Group II and Group III were exposed to gamma radiation at the 8th day. After the completion of all processes, Vitamin D, ADMA, SDMA and Hcy levels were measured by HPLC (High-performance liquid chromatography) method. Results: When the results of Group II and Group III were compared with each other, we achieved merely statistical significance in vitamin $D$ results $(p=0.04)$ but did not other parameters $(p>0.05)$. Conclusion: We observed that vitamin $D$ supplementation did not any effect on SDMA, ADMA, and Hcy that accompany possible endothelial dysfunction after gamma radiation exposure.

Key words: Gamma radiation; Endothelial dysfunction; Vitamin D; Homocysteine

\section{Access this article online}

Website:

http://nepjol.info/index.php/AJMS DOI: 10.3126/ajms.v12i1.31548

E-ISSN: 2091-0576

P-ISSN: 2467-9100

Copyright (c) 2021 Asian Journal of Medical Sciences

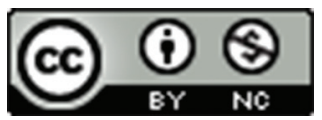

This work is licensed under a Creative Commons Attribution-NonCommercial 4.0 International License.

\section{INTRODUCTION}

Radiation, which is used for both the diagnosis and treatment, interacts with biomolecules in biological systems, causing molecules to gain or lose electrons. Unstable biomolecules with changing electron balance undergo deterioration in the system. ${ }^{1,2}$ Ionization occurs if radiation carries sufficient energy to detach one or more electrons from atoms or molecules. Radiation that is produced in this way is called ionizing radiation and a great amount of energy is consumed to produce radiation. ${ }^{3-5}$ Furthermore, unstable biological molecules initiate irreversible reactions, particularly membrane damage, in the cell or tissue through lipid peroxidation. The formation of free radicals is triggered by low-dose X-ray radiation or other types of radiation and free-radicals induce oxidative damage such 
as lipid peroxidation, protein and enzyme inactivation, and DNA broken lesions. ${ }^{5}$ Free-radical damage leads to apoptosis or necrosis in cells or tissues by causing lipid peroxidation, disruption of cell membrane integrity, protein and enzyme inactivation, and base modifications in nucleic acids. Radiotherapy provides tumor regression; however, it also causes oxidative damage in healthy tissues. ${ }^{6}$ Nitric oxide $(\mathrm{NO})$ is a functional molecule that is particularly prominent in the nervous and cardiovascular systems. Besides its neurotransmission effects, it also has vasodilator effects in the vascular system. ${ }^{6}$ Its level has been shown to increase in plasma and tissues with its necessary physiological effects and radiation effect. ${ }^{7}$ Increasing NO levels react with the superoxide formed together and induce the peroxynitrite formation. Peroxynitrite is particularly effective in nitration of tyrosines, which are included in the functional groups of enzymes, and oxidation of polyunsaturated fatty acids. ${ }^{8}$ Nitric oxide, which is an important molecule in physiological process and endothelial function, is produced from $\mathrm{L}$-arginine through the reaction catalyzed by NO synthase (NOS). ${ }^{9-11}$ Asymmetric dimethylarginine (ADMA), which is a NOS inhibitor, is formed by the methylation of arginine residues by protein arginine methyltransferases. ${ }^{12}$ Increased ADMA levels are associated with loss of endothelial function. ${ }^{13}$ Parallel to all these, radiation application has a negative effect on the endothelial line covering a total surface area of $4000-7000 \mathrm{~m}^{2}$ in the human body. ${ }^{14}$ High plasma homocysteine (Hcy) levels is another factor affecting the pathophysiology of endothelial dysfunction. Vitamin D has been shown to have a protective effect on endothelial dysfunction. ${ }^{15,16}$ There are studies reporting that vitamin $\mathrm{D}$ administration in particular prevents the increase in ADMA levels, which is effective in endothelial function or endothelial pathology. ${ }^{17}$

This study aimed to investigate the effect of vitamin $D$ administration on serum ADMA, symmetric dimethylarginine (SDMA), and Hcy levels in rats exposed to gamma radiation.

\section{MATERIALS AND METHODS}

\section{Determination of experimental groups}

A total of 24 female Wistar albino rats with a mean weight ranging 200-250 grams were used in this study. The rats were obtained from Gazi University Faculty of Medicine Laboratory Animal Breeding and Experimental Research Center (GUDAM). The animals were housed with food and water ad libitum under a 12-hour light/12-hour dark cycle at a room temperature of $25^{\circ} \mathrm{C}$ for four weeks. Experimental animals were properly prepared for study. For anesthesia, $40 \mathrm{mg} / \mathrm{kg}$ ketamine hydrochloride (Alfamine) and $8 \mathrm{mg} / \mathrm{kg}$ xylazine (Alfazyne) were administered through intraperitoneal injection. Blood samples were collected from rats with the help of a syringeand they wereeuthanized. The samples collected were centrifuged at $3500 \mathrm{rpm}$ for five minutes to separate serums and stored at $-80{ }^{\circ} \mathrm{C}$ until the time of analysis. Rats were divided into four groups namely Control Group ( $\mathrm{n}=6)$, Radiation group ( $\mathrm{n}=6$ ), Radiation + Vitamin D Group ( $\mathrm{n}=6$ ), and Vitamin D Group $(\mathrm{n}=6)$ and were housed in special cages in groups. No application was performed in the rats in the control group (Group I). Rats in the radiation group (Group II) were exposed to Cobalt radiation (612 cGy) in Gazi University Medical Faculty Radiation Oncology Unit. Vitamin D was administered to the Radiation + Vitamin D group (Group III) via oral gavage at 11.30 a.m. for a week.This application was stopped one week later, and cobalt radiation (612 cGy) was performed on the eighth day. Vitamin D was administered to the Vitamin D group (Group IV) via oral gavage at 11.30 a.m. for a week. Tissue samples and serums were collected under suitable conditions 24 hours after the procedures and were kept at $-80{ }^{\circ} \mathrm{C}$ until the time of analysis. The collected blood samples were first kept at $-40{ }^{\circ} \mathrm{C}$ and then at $-20{ }^{\circ} \mathrm{C}$ for a while before the study day, and they were, then, taken to room temperature. Then, allanalyses were performed. This study was approved by Gazi University Medical Faculty Local Animal Ethics Committee (Approval no. G.Ü.E.T.-10.081).

\section{LABORATORY MEASUREMENTS}

\section{Homocysteine Determination ( $\mu \mathrm{moL} / \mathrm{mL}$ )}

Homocysteine determination was performed by highperformance liquid chromatography (HPLC) on SHIMADZU DG-G 20 A3 device using the ImmuChrom Hcy assay kit. The RF-535 Fluorescence Detector was used. For the determination of Hcy, the sample was reduced and derivatized in one step. The albumin-bound and the oxidized Hcy was reduced and converted into a fluorescent probe. High molecular substances were removed during precipitation. Concentrations were calculated by the device according to the "internal standard method". Reagents are provided with the kit. Plasma calibrator, internal standard, reduction solution, derivative, and precipitation reagent were prepared by dissolving in Recon solution in accordance with the instructions specified in the kit. Furthermore, single mobile phase was provided with the kit.

\section{Determination of vitamin $D(\mu \mathrm{g} / \mathrm{mL})$}

Serum vitamin D levels were determined using Shimadzu DG-G 20 A3 HPLC system equipped with two SCL10-AVP pumps, one SLC-10-AVP controller, and one 


\section{Table 1: Median and IQR values for all groups}

\begin{tabular}{lcccc} 
& SDMA $(\boldsymbol{\mu} \mathbf{m o l} / \mathbf{l})$ & ADMA $(\boldsymbol{\mu m o l} / \mathbf{l})$ & Vitamin D $(\boldsymbol{\mu g} / \mathbf{m I})$ & Hcy $(\boldsymbol{\mu m o l} / \mathbf{m I})$ \\
\hline Group I $(\mathrm{n}=6)$ & $0.19(0.17-0.21)$ & $0.34(0.26-0.42)$ & $6.30(4.21-8.36)$ & $8.58(6.56-10.37)$ \\
Group II $(\mathrm{n}=6)$ & $0.32(0.27-0.41)$ & $0.36(0.28-0.40)$ & $2.56(1.11-3.48)$ & $9.25(7.51-11.02)$ \\
Group III $(\mathrm{n}=6)$ & $0.22(0.18-0.28)$ & $0.39(0.31-0.43)$ & $67.80(47.88-86.50)$ & $6.35(4.89-8.18)$ \\
Group IV $(\mathrm{n}=6)$ & $0.20(0.16-0.24)$ & $0.32(0.27-0.36)$ & $84.21(66.80-96.42)$ & $8.28(6.37-10.29)$ \\
\hline ADMA:Asymmetric dimethylarginine, SDMA: symmetric dimethylarginine, Hcy: homocysteine, IQR: interquartile range &
\end{tabular}

SPD-20A UV / vis detector. After deproteinization with a specific reagent and after purification with clean-up columns, the samples were injected directly into the HPLC system. The identification of vitamin $\mathrm{D}$ was performed on an RP C18 analytical column Poroshell EC $4.6 \times 50 \mathrm{~mm}$, $2.7 \mu \mathrm{m}$ (Agilent, Cernusco Sul Naviglio, Milano, Italy). The analyses were conducted using a mobile phase consisting of $80 \%$ acetonitrile and $20 \%$ water in isocratic elution mode with a flow rate of $0.8 \mathrm{~mL} / \mathrm{min}$. Injections were done using a six-port valve equipped with a $50 \mu 1$ loop. The detection was carried out at $265 \mathrm{~nm}$.

\section{ADMA determination ( $\mu \mathrm{moL} / \mathrm{L}$ )}

The analysis was performed using a Nucleosil Phenyl column $(25 \times 4.6 \mathrm{~mm} ; 7 \mu \mathrm{m}$; Supelco, USA $)$ via HPLC method on SHIMADZU DG-G 20 A3 device. Fluorescent detector was used for ADMA determination. Furthermore, since the broad-spectrum column was used in ADMA analysis, SDMA determination was performed simultaneously with the ADMA peak.

\section{Statistical analysis}

Statistical analysis was performed using SPSS 15.0 software for Windows. Numerical variables were expressed as median and interquartile range. The normality of the data was analyzed using skewness and kurtosis values, Kolmogorov-Smirnov test, Shapiro-Wilk test and histogram distribution charts. Spearman's rank correlation coefficient was used since parametric test conditions could not be provided for correlation analysis. The significance of the difference between the groups in terms of laboratory measurements was investigated using the Mann-Whitney $\mathrm{U}$ test. A p value of $<0.05$ was considered statistically significant.

\section{RESULTS}

There was a significant difference only in SDMA levels between Group I and Group II ( $\mathrm{p}=0.010)$. The SDMA levels of Group II were found to be statistically significantly higher than those of Group I. No statistically significant difference was found between Group I and Group II in terms of ADMA, Vitamin D, and Hcy levels ( $p>0.05$ ). The comparison of Group II and Group III showed that there was a significant difference between the

\begin{tabular}{lcccc}
\multicolumn{5}{l}{ Table 2: P values of compared groups } \\
\hline & $\begin{array}{c}\text { Group } \\
\text { I- II }\end{array}$ & $\begin{array}{c}\text { Group } \\
\text { II-III }\end{array}$ & $\begin{array}{c}\text { Group } \\
\text { I- IV }\end{array}$ & $\begin{array}{c}\text { Group } \\
\text { III-IV }\end{array}$ \\
\hline SDMA $(\mu \mathrm{mol} / \mathrm{l})$ & $\mathrm{p}=0.006^{*}$ & $\mathrm{p}=0.078$ & $\mathrm{p}=0,575$ & $\mathrm{p}=0,173$ \\
ADMA $(\mu \mathrm{mol} / \mathrm{l})$ & $\mathrm{p}=0.522$ & $\mathrm{p}=0.575$ & $\mathrm{p}=0,423$ & $\mathrm{p}=0,200$ \\
Vitamin $\mathrm{D}(\mu \mathrm{g} / \mathrm{ml})$ & $\mathrm{p}=0.010^{*}$ & $\mathrm{p}=0.004^{*}$ & $\mathrm{p}=0,004^{*}$ & $\mathrm{p}=0,262$ \\
Hcy $(\mu \mathrm{mol} / \mathrm{ml})$ & $\mathrm{p}=0.749$ & $\mathrm{p}=0.078$ & $\mathrm{p}=0,337$ & $\mathrm{p}=0,109$ \\
\hline $\begin{array}{l}\mathrm{p}<0.05^{*} \\
\text { ADMA: Asymmetric dimethylarginine, SDMA: symmetric dimethylarginine, }\end{array}$ \\
Hcy: homocysteine
\end{tabular}

groups in terms of vitamin $\mathrm{D}$ levels $(\mathrm{p}=0.040)$ whereas no statistically significant difference was observed in terms of other parameters $(p>0.05)$. Similarly, while a statistically significant difference was observed between Group I and Group IV only in terms of vitamin D levels $(\mathrm{p}=0.040)$, no significant difference was found for other parameters ( $p>0.05)$. There was no statistically significant difference between Group III and Group IV in terms of all parameters $(\mathrm{p}>0.05)$. The mean, standard deviation and statistical significance levels ( $p$ values) of the groups are shown in Table 1 and Table 2, respectively. The correlation results of the parameters studied are presented in Table 3 and Table 4.

\section{DISCUSSION}

This study has investigated the possible effects of gamma radiation on SDMA, ADMA, Hcy and vitamin D levels. Considering the results obtained, the first remarkable finding was that the mean SDMA levels of the rats in the gamma irradiation group were statistically significantly higher compared to those of the control group. The second most remarkable finding was that the Hcy levels of the group receiving gamma radiation + vitamin $\mathrm{D}$ were lower than the other groups. However, this decrease in Hcy levels was not statistically significant between these two groups.

In a study by Kantar et al. ${ }^{18}$ investigating the effect of melatonin applied to fructose-fed rats on the pathology of endothelial dysfunction, ADMA and Hcy levels, potential markers for endothelial dysfunction, were analyzed. The authors found that ADMA and Hcy levels were lower in the fructose-plus-melatonin group than the fructose group and reported that melatonin administration caused a decrease in ADMA and Hcy levels, reducing the risk of 


\begin{tabular}{|c|c|c|c|c|c|c|}
\hline & \multicolumn{2}{|c|}{ SDMA-ADMA ( $\mu \mathrm{mol} / \mathrm{l})$} & \multicolumn{2}{|c|}{ SDMA ( $\mu \mathrm{mol} / \mathrm{l})$ - Vitamin D $(\mu \mathrm{g} / \mathrm{ml})$} & \multicolumn{2}{|c|}{ SDMA $(\mu \mathrm{mol} / \mathrm{l})-\mathrm{Hcy}(\mu \mathrm{mol} / \mathrm{ml})$} \\
\hline & $\mathbf{P}$ & $\mathbf{r}$ & $\mathbf{P}$ & $\mathbf{r}$ & $p$ & $\mathbf{r}$ \\
\hline Group I $(n=6)$ & $0.02^{*}$ & 0.632 & 0.56 & 0.242 & 0.87 & 0.269 \\
\hline Group II $(n=6)$ & $0.03^{*}$ & 0.561 & 0.41 & -0.321 & 0.25 & 0.163 \\
\hline Group III $(n=6)$ & $0.01^{* *}$ & -0.858 & 0.55 & -0.159 & 0.28 & 0.112 \\
\hline Group IV $(n=6)$ & $0.01^{* *}$ & -0.774 & 0.63 & -0.214 & 0.41 & 0.155 \\
\hline
\end{tabular}

Table 4: Correlation results of groups

\begin{tabular}{|c|c|c|c|c|c|c|}
\hline & \multicolumn{2}{|c|}{ Vitamin D $(\mu \mathrm{g} / \mathrm{ml})-$ Hcy $(\mu \mathrm{mol} / \mathrm{ml})$} & \multicolumn{2}{|c|}{ ADMA ( $\mu \mathrm{mol} / \mathrm{l})$ - Vitamin D $(\mu \mathrm{g} / \mathrm{ml})$} & \multicolumn{2}{|c|}{ ADMA $(\mu \mathrm{mol} / \mathrm{l})-\mathrm{Hcy}(\mu \mathrm{mol} / \mathrm{ml})$} \\
\hline & $\mathbf{P}$ & $\mathbf{r}$ & $\mathbf{P}$ & $\mathbf{r}$ & $p$ & $\mathbf{r}$ \\
\hline Group I $(n=6)$ & 0.10 & 0.118 & 0.61 & 0.217 & 0.45 & 0.222 \\
\hline Group II (n=6) & 0.13 & -0.254 & 0.56 & -0.299 & 0.09 & 0.176 \\
\hline Group III (n=6) & 0.08 & -0.125 & 0.87 & 0.148 & 0.12 & -0.282 \\
\hline Group IV (n=6) & 0.90 & 0.194 & 0.11 & 0.183 & 0.66 & 0.188 \\
\hline
\end{tabular}

$\mathrm{p}<0.05$
ADMA: Asymmetric dimethylarginine, SDMA: symmetric dimethylarginine, Hcy: homocysteine

cardiovascular diseases. Korandji et al. ${ }^{19}$ investigated the cardiovascular function, oxidative stress and ADMA levels in fructose-hypersensitive rat models and found that there was an increase in ADMA levels secondary to oxidative stress developing in the early period due to the development of hypertension in rats fed with fructose for two weeks. Oxidative stress and free radicals that occur over time cause damage to the arteries, resulting in endothelial dysfunction. In studies examining the mechanisms that can prevent this situation, vitamin D deficiency and endothelial dysfunction were reported to be correlated. ${ }^{15,20-22}$ In a study by Wu et al. ${ }^{23}$ investigating the effects of standard hypertensive therapy, folic acid and B12 on ADMA and Hcy levels in hypertensive patients, the authors found that folic acid, B12 and standard hypertensive therapy caused a decrease in ADMA and Hcy levels in hypertensive patients. Elevated ADMA and Hcy levels are a very important marker for endothelial dysfunction. Thus, an increase in these markers indicates that oxidant mechanisms are active, and there is damage at the endothelial level.

Karakaş et al. ${ }^{24}$ investigated the effects of vitamin D levels and vitamin D supplementation on endothelial dysfunction in patients with chronic renal failure and reported that endothelial dysfunction regressed in patients who received vitamin D supplementation and that Vitamin D supplementation could prevent chronic renal failure in patients receiving hemodialysis. Similarly, Zhang et al. ${ }^{25}$ suggested that vitamin D supplementation may have a positive effect on endothelial dysfunction in patients with chronic renal failure who were not suitable for dialysis. However, unlike other studies, Pincombe et al. ${ }^{26}$ argued in their meta-analysis study that vitamin $\mathrm{D}$ supplementation had no effect on endothelial dysfunction and that more evidence should be presented before vitamin D supplementation was applied for the treatment of endothelial dysfunction. Torino et al. ${ }^{27}$ administered vitamin $\mathrm{D}$ to patients with stage III and IV chronic kidney disease for 12 weeks and found that there was no change in ADMA and SDMA levels.

In the present study, comparison of the group of rats exposed to radiation with the group receiving radiation plus vitamin D showed a decrease in SDMA and Hcy levels in the radiation plus vitamin $\mathrm{D}$ group while there was an increase in the ADMA levels. However, the changes were not statistically significant. Similarly, Grübler et al. ${ }^{17}$ investigated the effect of vitamin $\mathrm{D}$ administration on ADMA and SDMA levels in hypertensive patients and concluded that vitamin $\mathrm{D}$ administration had no effect on ADMA and SDMA levels.

\section{CONCLUSION}

In conclusion, vitamin $\mathrm{D}$ administration had no effect on SDMA, ADMA and Hcy levels accompanying possible endothelial dysfunction pathology following exposure to gamma radiation. Considering the results of the present study and the abovementioned studies, we believe that there is a need for more evidence to understand the mechanism of action and results of the use of vitamin D supplementation to prevent the pathology of endothelial dysfunction. We further believe that this study will shed light on similar studies to be carried out in the future.

\section{Limitations of the study}

This study had several limitations although it was carefully prepared. The number of subjects included in the study can 
be increased, and studies can be conducted with different gamma radiation doses. Secondly, parathyroid hormone, calcium and phosphorus levels can be evaluated together with vitamin $\mathrm{D}$ levels, and studies can be conducted to investigate the endothelial damage following the vitamin D supplementation at different cut-off points and different doses.

\section{ACKNOWLEDGEMENT}

The authors take this opportunity to thank Department of Medical Biochemistry and Radiation Oncology for their whole hearted support for this study.

\section{REFERENCES}

1. Ocolotobiche EE, Banegas $Y C$ and Güerci AM. Modulation of ionizing radiation-induced damage in human blood lymphocytes by in vivo treatment with resveratrol. Int J Radiat Biol. 2019; 95: 1220-1225.

https://doi.org/10.1080/09553002.2019.1625489

2. Anand AJ, Dzik WH, Imam A and Sadrzadeh SM. Radiationinduced red cell damage: role of reactive oxygen species. Transfusion. 1997; 37: 160-165.

https://doi.org/10.1046/j.1537-2995.1997.37297203518.x

3. Pisoschi AM and Pop A. The role of antioxidants in the chemistry of oxidative stress: A review. Eur J Med Chem. 2015; 97: 55-74. https://doi.org/10.1016/j.ejmech.2015.04.040

4. Yakovlev VA. Role of nitric oxide in the radiation-induced bystander effect. Redox biology. 2015; 6: 396-400.

https://doi.org/10.1016/j.redox.2015.08.018

5. Ohta S, Matsuda S, Gunji M and Kamogawa A. The role of nitric oxide in radiation damage. Bio Pharm Bull. 2007; 30: 1102-1107. https://doi.org/10.1248/bpb.30.1102

6. Chakraborti A, Gulati K and Ray A. Possible role of nitric oxide (NO) in the regulation of gender related differences in stress induced anxiogenesis in rats. Nitric oxide. 2014; 43: 74-80. https://doi.org/10.1016/j.niox.2014.08.005

7. Hong CW, Kim YM, Pyo H, Lee JH, Kim S, Lee S, et al. Involvement of inducible nitric oxide synthase in radiationinduced vascular endothelial damage. J Radiat Res. 2013; 54: 1036-1042.

https://doi.org/10.1093/jrr/rrt066

8. Förstermann $\mathrm{U}, \mathrm{Xia} \mathrm{N}$ and $\mathrm{Li} \mathrm{H}$. Roles of Vascular Oxidative Stress and Nitric Oxide in the Pathogenesis of Atherosclerosis. Circ Res. 2017; 120: 713-735.

https://doi.org/10.1161/CIRCRESAHA.116.309326

9. Tousoulis D, Kampoli AM, Tentolouris C, Papageorgiou N and Stefanadis C. The role of nitric oxide on endothelial function. Curr Vasc Pharmacol. 2012; $10: 4-18$. https://doi.org/10.2174/157016112798829760

10. Omanwar $S$ and Fahim M. Mercury Exposure and Endothelial Dysfunction: An Interplay Between Nitric Oxide and Oxidative Stress. Int J Toxicol. 2015; 34: 300-307. https://doi.org/10.1177/1091581815589766

11. Saran U, Mani KP, Balaguru UM, Swaminathan A, Nagarajan S, Dharmarajan AM, et al. SFRP4 signalling of apoptosis and angiostasis uses nitric oxide-cGMP-permeability axis of endothelium. Nitric oxide. 2017; 66: 30-42.

https://doi.org/10.1016/j.niox.2017.02.012

12. Siekmeier R, Grammer T and März W. Roles of oxidants, nitric oxide, and asymmetric dimethylarginine in endothelial function. J Cardiovasc Pharmacol. 2008; 13: 279-297. https://doi.org/10.1177/1074248408326488

13. Bartnicki P, Kowalczyk M, Franczyk-Skóra B, Baj Z and Rysz J. Evaluation of Endothelial (dys)Function, Left Ventricular Structure and Function in Patients with Chronic Kidney Disease. Curr Vasc Pharmacol. 2016; 14: 360-367. https://doi.org/10.2174/1570161114666160112142403

14. Weiss JF and Landauer MR. Radioprotection by antioxidants. Ann N Y Acad Sci. 2000; 899: 44-60. https://doi.org/10.1111/j.1749-6632.2000.tb06175.x

15. Federico A, Dallio M, Masarone M, Gravina AG, Sarna RD, Tuccillo $C$, et al. Evaluation of the Effect Derived from Silybin with Vitamin D and Vitamin E Administration on Clinical, Metabolic, Endothelial Dysfunction, Oxidative Stress Parameters, and Serological Worsening Markers in Nonalcoholic Fatty Liver Disease Patients. Oxidative Med Cell Longev. 2019; 2019: 8742075. https://doi.org/10.1155/2019/8742075

16. Muscogiuri G, Annweiler C, Duval G, Karras S, Tirabassi G, Salvio $G$, et al. Vitamin D and cardiovascular disease: From atherosclerosis to myocardial infarction and stroke. Int J Cardiol. 2017; 230: 577-584.

https://doi.org/10.1016/j.ijcard.2016.12.053

17. Grübler MR, Gaksch M, Kienreich K, Verheyen ND, Schmid J, Müllner C, et al. Effects of Vitamin D3 on asymmetric- and symmetric dimethylarginine in arterial hypertension. J Steroid Biochem Mol Biol. 2018; 175: 157-163. https://doi.org/10.1016/j.jsbmb.2016.12.014

18. Kantar Ş, Türközkan N, Bircan FS and Paşaoğlu ÖT. Beneficial effects of melatonin on serum nitric oxide, homocysteine, and ADMA levels in fructose-fed rats. Phar Biol. 2015; 53: 1035-1041. https://doi.org/10.3109/13880209.2014.957782

19. Korandji C, Zeller M, Guilland JC and Collin B. Time course of asymmetric dimethylarginine (ADMA) and oxidative stress in fructose-hypertensive rats: a model related to metabolic syndrome. Atherosclerosis. 2011; 214: 310-315.

https://doi.org/10.1016/j.atherosclerosis.2010.11.014

20. Franca Gois PH, Wolley M, Ranganathan D and Seguro AC. Vitamin D Deficiency in Chronic Kidney Disease: Recent Evidence and Controversies. Int J Environ Res. 2018; 15. https://doi.org/10.20944/preprints201807.0320.v1

21. Vila Cuenca M, Ferrantelli E, Meinster E,Pouw SM, Cevic IK, de Menezes RX, et al. Vitamin D Attenuates Endothelial Dysfunction in Uremic Rats and Maintains Human Endothelial Stability. J Am Heart Assoc. 2018; 7: e008776. https://doi.org/10.1161/JAHA.118.008776

22. Podzolkov VI, Pokrovskaya AE and Panasenko OI. Vitamin D deficiency and cardiovascular pathology. Ter Arkh. 2018; 90: 144-150.

https://doi.org/10.26442/terarkh2018909144-150

23. Wu CJ, Wang L, Li X, Wang CX, Ma JP and Xia XS. [Impact of adding folic acid, vitamin $\mathrm{B}(12)$ and probucol to standard antihypertensive medication on plasma homocysteine and asymmetric dimethylarginine levels of essential hypertension patients]. Zhonghua xin xue guan bing za zhi. 2012; 40: 1003-1008.

24. Karakas Y, Sahin G, Urfali FE, Bal C, Degirmenci NA and Sirmagul B. Effect of vitamin D supplementation on endothelial dysfunction in hemodialysis patients. Hemodial Int. 2017; 21: 97-106. https://doi.org/10.1111/hdi.12439 
25. Zhang $Q$, Zhang $M$, Wang $H$, Sun $C$, Feng $Y$, Zhu W, et al. Vitamin $D$ supplementation improves endothelial dysfunction in patients with non-dialysis chronic kidney disease. Int Urol Nephrol. 2018; 50: 923 - 927.

https://doi.org/10.1007/s11255-018-1829-6

26. Pincombe NL, Pearson MJ, Smart NA, King N and Dieberg G. Effect of vitamin $D$ supplementation on endothelial function
- An updated systematic review with meta-analysis and metaregression. Nutr Metab Cardiovasc Dis. 2019; 29: 1261-1272. https://doi.org/10.1016/j.numecd.2019.08.005

27. Torino C, Pizzini P, Cutrupi S and Tripegi R. Vitamin D and methylarginines in chronic kidney disease (CKD). PloS one. 2017; 12: e0185449.

https://doi.org/10.1371/journal.pone.0185449

\section{Author's Contribution:}

ED- Concept and design of the study; prepared first draft of manuscript; DA- Interpreted the results; reviewed the literature and manuscript preparation, Statistically analysed and interpreted, preparation of manuscript and revision of the manuscript; AA- Concept, coordination, review of literature and manuscript preparation; MA- Concept, coordination, review of literature and manuscript preparation.

\section{Work attributed to:}

Gazi University Faculty of Medicine, Ankara. Turkey.

\section{Orcid ID:}

Erdem Kahraman- https://orcid.org/0000-0002-6849-6669

Dr. Durmuş Ayan-1D https://orcid.org/0000-0003-2615-8474

Prof. Dr. Aysel Arıcıoğlu-(i) https://orcid.org/0000-0001-5076-9828

Prof. Dr. Müge Akmansu- iD https://orcid.org/0000-0002-5747-2522

Source of Funding: Coordinatorship of Scientific Research Projects, Conflict of Interest: None 